\title{
Retrograde Ejaculation Following Lumbopelvic Sympathetic Neurolysis - A Case Series
}

\author{
Ajax Yang, MD ${ }^{1}$, Ryan R. Ramsook, MD ${ }^{1}$, and Corey W. Hunter, MD ${ }^{1,2}$
}

Background: Sympathetic neurolysis, or sympathectomy, is an established modality for the treatment of chronic pain. In cases of chronic pelvic pain (CPP), the ganglion of impar (GI) and the superior hypogastric plexus (SHP) are widely accepted targets for such therapy.

Objective: While diagnostic injections typically predate any neurolysis for the purpose of ascertaining any potential efficacy for interrupting a particular pathway, careful attention is equally paid to evaluate for possible adverse events - in the case of lumbopelvic neurolysis, retrograde ejaculation (RE) is one such possibility.

Study Design: A case series.

Setting: An outpatient pain management clinic. Methods: We present 3 male patients with CPP treated who underwent neurolytic procedures targeting the $\mathrm{GI}$ and SHP.

Results: The first patient developed RE after undergoing a simultaneous neurolysis of both the SHP and GI, in the same sitting. The second and third patients both experienced temporary RE immediately after diagnostic blockades of the SHP, following GI neurolysis that was performed several weeks prior.
Limitations: Cause-effect conclusions cannot be drawn from the results of a case series.

Conclusions: $\mathrm{RE}$ is a potential consequence of combined or serial SHP and GI neurolysis. While neurolysis of either the GI or SHP individually have not been known to cause RE in men, this case series demonstrates the potential risk in causing it when both structures are simultaneously incapacitated in some form; as such, the authors recommend against both structures being ablated or disabled concurrently without careful evaluation with temporary blockades first. In an effort to avoid such a complication or evaluate for the possibility in a particular individual, we recommend that an individual with CPP, who has already been treated with a neurolysis, undergoes diagnostic blocks first on whichever of the 2 structures has not yet been ablated to carefully evaluate if $R E$ will occur.

Key words: Retrograde ejaculation, superior hypogastric plexus, ganglion impar; neurolysis, chronic pelvic pain, male infertility, diagnostic block
Neurolysis is an established therapy for the treatment of certain types of chronic pain with an acceptable risk-benefit ratio (1). Neurolysis includes a

From: ${ }^{1}$ Department of Rehabilitation Medicine, Icahn School of Medicine at Mount Sinai, New York, New York; ${ }^{2}$ Ainsworth Institute of Pain Management, New York, New York

Author for correspondence: Ajax Yang, MD

Address: Ichan School of Medicine at Mount Sinai Hospital Rehabilitation Medicine, 1 Gustave L. Levy Place,

New York, New York 10029

E-mail: yang.ajax@gmail.com variety of different procedures (i.e., radiofrequency ablation, cryoablation, chemical neurolysis, etc.) (2) with the central premise of destroying a pain transmitting nerve, or at the very least limiting its ability to transmit pain, all the while preserving vital surrounding structures. Perhaps the greatest utility of neurolysis is in cases where surgical treatment is not the preferred curative method or there is simply nothing that can be outright "corrected" (e.g., Complex Regional Pain Syndrome or CRPS) (3). Regardless of the exact premise, neurolysis can serve to decrease a patient's pain simply by destroying its pathway to the cognitive centers in the brain. 
As it relates to chronic pelvic pain (CPP), rarely is there an obvious defect or detectable abnormality one can point to as the pain generator that can be fixed procedurally. In cases of pudendal entrapment (4), endometriosis (5), pelvic congestion syndrome (6), and the like, there is a relatively obvious pathophysiology one can potentially rectify and potentially repair. In other cases, when the cause or source of discomfort is not readily apparent, neurolysis may be the more acceptable treatment option as it is dependent on the route of the pain signals and not the cause or source.

The key to a successful neurolysis is the identification of the key conduits or neural pathways through which the pain signals are traveling (7). This is typically accomplished through the use of diagnostic injections (8) whereby a physician will inject a sodium channel blocker, such as lidocaine or bupivacaine, on a nerve, group of nerves, ganglion, plexus, etc. If the pain is improved during the time the target is under the influence of the injectate, it stands to reason that the target may be in part responsible for transmitting pain. In the case of CPP, pain pathways are often rooted in the sympathetic nervous system $(9,10)$ - in particular the ganglion of impar (GI) and the superior hypogastric plexus (SHP).

Neurolysis of the GI and SHP was first described by Plancarte in 1990 (11) as a means of treating pelvic pain secondary to cancer. These have since been adapted for the treatment of non-malignant pain due to their efficacy and low potential for complication $(9,10,12)$. While the GI and SHP are accepted targets for neurolysis, certain male patients may potentially be at risk for RE. We present a case series of 3 men with CPP who experience RE after blockade/neurolysis of the SHP, following a GI several weeks prior.

\section{Retrograde Ejaculation}

Male infertility accounts for roughly $20 \%$ of all infertilities among couples of reproductive age (13-15). Although the prevalence of RE has been estimated $0.3-3.2 \%$ of all male infertility (16-19), the true prevalence may be higher due to under-reporting from the fear of social stigmatization (20). It has been shown that infertile men who desire fatherhood are at a higher risk to experience low self-esteem, depression, anxiety, and marital discord compared to their healthy cohorts $(15,21-23)$. Furthermore, male infertility treat- ment creates a significant burden to healthcare costs. Over $60 \%$ of men who pursue assisted reproductive treatments spend over $\$ 15,000$ out-of-pocket, and overall, these patients typically spent $16-20 \%$ of their annual incomes on infertility treatment in the US (24). Therefore, preventing iatrogenic male infertility, such as RE following pelvic sympathetic neurolysis in treating pelvic pain, is of great importance among interventional pain physicians.

\section{Physiology of Ejaculation: The Role of Sympa- thetic Nervous System on Ejaculation}

Ejaculation is divided into emission and expulsion (Fig. 1). Both phases are collectively under the control of the lumbar sympathetic nervous system and its network of conduits (i.e., the SHP, hypogastric plexus, and ending most caudally at the $\mathrm{GI}$ ) that provide $\alpha-1$ adrenergic innervation to the smooth muscle of the bladder neck, prostate, vas deferens, and seminal vesicles (25). During emission, the first phase of ejaculation, the prostate and seminal vesicle contract to deposit seminal fluid into the posterior urethra and simultaneously tighten the bladder neck by increasing the bladder neck tone in response to the increased sympathetic input (26). With the bladder neck tightly closed and the external urinary sphincter in a relaxed state, the semen is positioned to travel in the direction of least resistance (i.e., towards the urethral meatus). Following emission, the semen is propelled through the urethral meatus and out of the penis during expulsion. Sympathetic signals increase the bladder neck tone and prevent a retrograde flow of the semen into the bladder. Furthermore, sympathetic ganglia of T10-L2 along with parasympathetic sacral fibers carry sensory input to the ejaculatory centers in the brain ( 2 in the hypothalamus, medial preoptic and paraventricular nucleus, and one in the periaqueductal grey midbrain) (27).

\section{Physiology of Ejaculation: The Role of Parasym- pathetic Nervous System on Ejaculation}

Sacral nerve roots S2-4 give rise to the cavernous nerves of the penis, which are mainly parasympathetic and responsible for the relaxation of smooth muscle, allowing blood to flow into cavernous spaces in the corpora of the penis, resulting in erection. Pudendal and pelvic nerves also contain somatic neurons from S2-S4 nerve roots that cause rhythmic contraction and relaxation of the ischiocavernosus, 


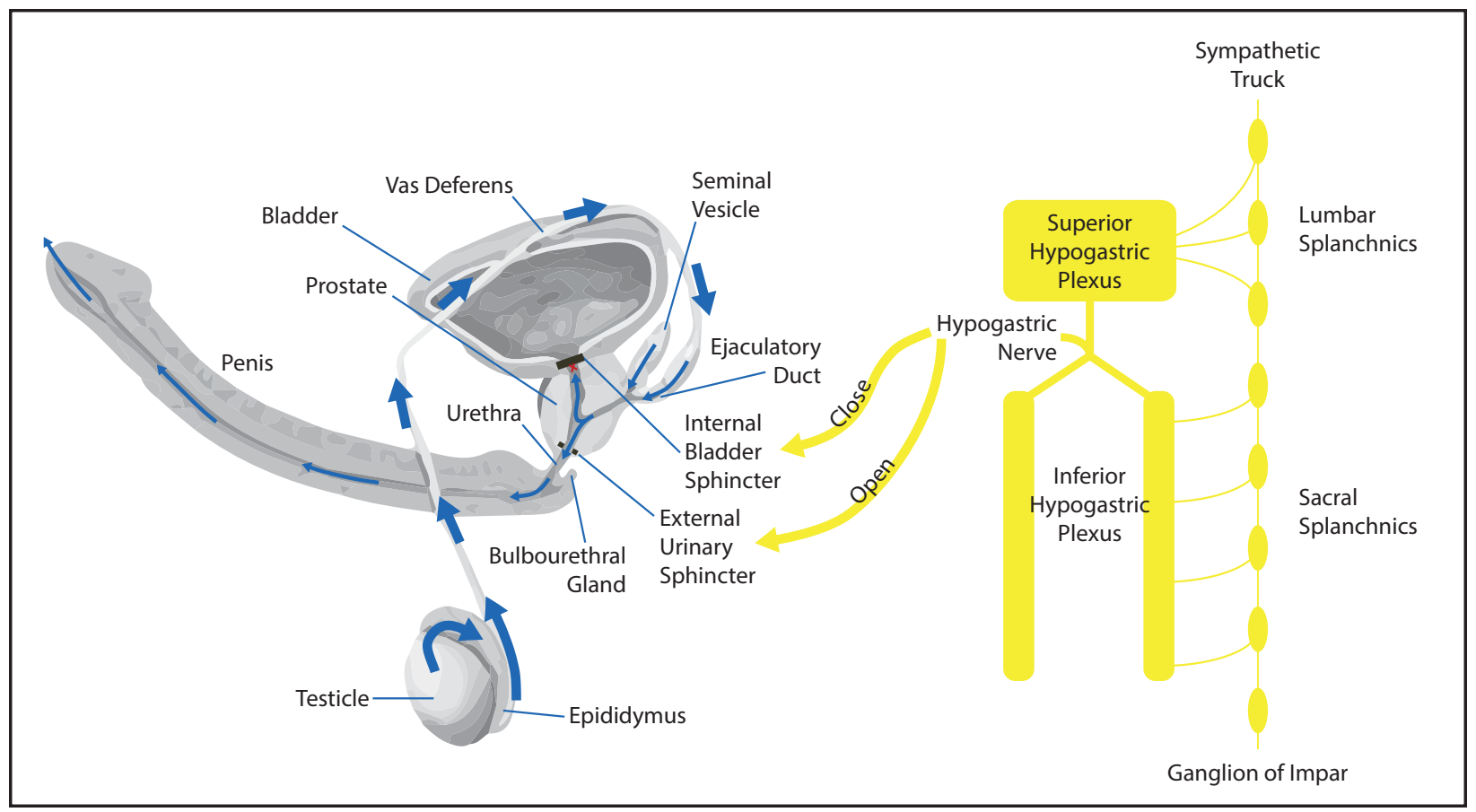

Fig. 1. A schematic representation of normal physiological ejaculation under sympathetic nervous system control.

bulbospongiosus, and pelvic floor muscles to further facilitate antegrade semen emission (26).

\section{Pathophysiology of Retrograde Ejaculation}

In RE, bladder neck closure is impaired while all of the other elements of ejaculatory mechanisms remain intact. The retrograde semen trajectory will result in reduced expelled semen volume. When the semen volume is less than $2 \mathrm{~mL}$ on at least 2 separate occasions, the diagnosis of RE and hypospermia should be considered (28). RE can occur partially (decreased ejaculate volume following orgasm) or completely (total absence of ejaculate i.e., aspermia). Clinically, patients may report dry orgasm or cloudy urine following orgasm. The diagnosis of $R E$ is made by detecting the presence of spermatozoa or fructose in a post-ejaculatory urine sample $(29,30)$. Causes of $\mathrm{RE}$ can be grouped into 3 categories - mechanical, pharmacologic, and neurologic:

Mechanical - This is the most common cause of bladder neck injury leading to an incomplete closure, typically following transurethral resection of the prostate (TURP) (31) or the placement of surgical instrumentation to the lumbar spine (32). Lymph node dissections (33-36), colorectal surgery, lumbar sympathectomy, and retroperitoneal surgeries all carry a risk of causing collateral damage that could potentially lead to retrograde ejaculation (37). Damage to the SHP is also known to result in RE, urinary urgency, and incontinence (33-36). In addition to SHP, pudendal nerve injury can occur during pelvic surgeries $(4,38)$

Pharmacologic - $\alpha$-receptor antagonists are the most common culprits causing RE due to their influence on the smooth muscle of the bladder neck and their ability to reduce tension. Tamsulosin, an a1adrenergic blocker, has been shown to significantly decrease bulbospongiosus muscular contraction force to expel semen in the anterograde direction (39). Similarly, antipsychotic medications (i.e., chlorpromazine, thioridazine, and risperidone) are potent a1-adrenergic receptor antagonists known to cause RE $(40,41)$. Serotonin has been shown to affect a subset of inhibitory 5-HT receptors found in the semi- 
nal vesicles, vas deferens, urethra, and prostate to down-regulate ejaculation (42). Selective serotonin reuptake inhibitors (SSRI), such as fluoxetine and sertraline, increase the bioavailability of serotonin, potentially leading to $\mathrm{RE}$

Neurologic - Stroke, multiple sclerosis, and chronic, uncontrolled diabetes can all lead to an autonomic neuropathy that may impair the sympathetic innervation of the bladder neck closure. Diabetic neuropathy is accountable for $5-18 \%$ cases of $\operatorname{RE}(37,43)$.

\section{Chronic Pelvic Pain (CPP)}

CPP is a broad diagnosis consisting of a variety of conditions and syndromes that appear to evolve into a neuropathic state that is typically recalcitrant to conservative measures (44). It affects both men and women with an estimated prevalence ranging from $4-40 \%(45)$. While the pathophysiology is still poorly understood, there are a number of conditions known to increase one's predilection toward developing it. In 2013, Hunter et al (44) extensively reviewed the pathophysiology and causes of CPP, including interstitial cystitis/painful bladder syndrome, coccydynia, anorectal pain, and chronic prostatitis/prostadynia
(Table 1). Depending on the etiology, a typical treatment approach often begins with physical therapy, antibiotics, antidepressants, and/or oral analgesics. Failure of conservative therapies is almost inevitable in moderate to severe cases, thus requiring interventional pain procedures. While there is no consensus on what particular procedure or region should be targeted before another, 2 accepted targets are the GI and SHP (45).

\section{Neurolytic Targets for Treating CPP}

\section{SHP}

The SHP is a network of nerve fibers that originates from the T10-L2 (46). The SHP is located in the retroperitoneal space at the bifurcation of the aorta, merges on the anterior to the L5/S1 intervertebral disc, and travels caudally over the sacral promontory situated one $\mathrm{cm}$ from the midline and $2 \mathrm{~cm}$ medial to the ureter and iliac artery (47). The SHP, which contains purely sympathetic fibers, continues to travel caudally and divides into bilateral hypogastric plexuses and eventually contributes to the lateral branches of the inferior hypogastric plexuses in the

Table 1. A summary of the pathological causes of pelvic pain (44).

\begin{tabular}{|c|c|}
\hline Pathological Causes of Pelvic Pain & Highlights \\
\hline \multirow{4}{*}{$\begin{array}{l}\text { Interstitial cystitis/painful bladder } \\
\text { syndrome }\end{array}$} & *It is chronic and a diagnosis of exclusion with unknown etiology. \\
\hline & $\begin{array}{l}\text { *The likely causes: urothelial lining defects with exposure to mast cells (the most likely cause), } \\
\text { autoimmune disorders, infection, pelvic floor dysfunction, toxins, and bladder wall defects. }\end{array}$ \\
\hline & $\begin{array}{l}\text { *It is characterized by frequency, urgency, dyspareunia, nocturia, and pelvic and/or abdominal } \\
\text { pain. }\end{array}$ \\
\hline & *It is diagnosed via cystoscopy, hydrodistention, and biopsy. \\
\hline \multirow{4}{*}{ Chronic prostatitis/prostadynia } & *Affects men \\
\hline & *It is a diagnosis of exclusion. \\
\hline & *The associated symptoms: frequency, dysuria, poor urinary flow, and genital or perineal pain. \\
\hline & $\begin{array}{l}* 4 \text { categories of prostatitis, ranging from category I-IV, with category III being the most common } \\
\text { type in men }>50 \text { years of age and 3rd most common in those }>50 \text { years of age. }\end{array}$ \\
\hline \multirow[b]{2}{*}{ Coccygodynia } & *Coccygeal pain worsened by sitting. \\
\hline & $\begin{array}{l}\text { *The possible causes are trauma, infection, neoplasm, and osteoarthritis of sacrococcygeal joint } \\
\text { or referred pain from the surrounding visceral structure and pelvic floor spasm. }\end{array}$ \\
\hline \multirow[b]{2}{*}{ Vulvodynia } & *It is characterized by non-painful stimuli that result in painful sensation in the vulva. \\
\hline & $\begin{array}{l}\text { *There are several proposed mechanisms including increased muscle tone in superficial perineum } \\
\text { and neurogenic inflammation. }\end{array}$ \\
\hline \multirow{3}{*}{ Anorectal pain } & *It is a diagnosis of exclusion. \\
\hline & *It is often associated with levator ani syndrome, coccygodynia, and proctalgia fugax. \\
\hline & *It is likely caused by neuropathic pain affecting the pelvic floor. \\
\hline
\end{tabular}


pelvis, while some splanchnic branches (S2-S4) make up the medial portion $(48,49)$.

\section{GI}

The $\mathrm{GI}$, also known as sacrococcygeal ganglion or ganglion of Walther, is a singular retroperitoneal structure located roughly at the level of the sacrococcygeal junction. The $\mathrm{Gl}$ is the most caudal segment of the confluence of the 2 sacral sympathetic chains as they pass anteromedially over the sacrum, with some anatomical variability between the sacrococcygeal junction and the lower segment of the first coccyx (50). Pelvic splanchnic nerves carry parasympathetic nerve fibers to coalesce with sympathetic fibers at the level $\mathrm{Gl}$ as well. The $\mathrm{Gl}$ also contains visceral afferent signals from the perineum, distal rectum/anus, urethral and distal vagina/scrotum (51). Blocking the $\mathrm{GI}$ provides visceral and sympathetic pain relief from the perineal region $(52-54,58)$.

\section{Rationale for SHPIGI Neurolysis in the Treatment of CPP}

Understanding the neuroanatomy in the lumbopelvic region provides the basis for targeting the sympathetic nervous system in treating CPP. Regardless of the pain source, the noxious stimuli of CPP can be transmitted via the sympathetic nervous system (i.e., SHP and/or GI) to the spinal cord then to the brain. Starting at the end organ, the afferent nociceptive signals travel up the unmyelinated postganglionic fibers toward the corresponding paravertebral ganglion and the gray rami communicans. At the paravertebral ganglion, the nociceptive stimuli may continue to propagate into the lateral grey column of the spinal cord through the myelinated fibers of the white rami communicans from T1-L2 into the spinal cord, or the stimuli may travel cephalad or caudal to a sympathetic paravertebral ganglion at the level(s) above or below before going into the spinal cord via the white rami communicans. The latter is specific to signals that originate caudal to $L 2$ because white rami communicans are absent below $L 2$. The signals that originate caudal to $L 2$ travel by postganglionic fibers to the corresponding grey rami communicans before joining the paravertebral sympathetic chain and continue cephalad until L2, or possibly higher, before transitioning to white rami communicans and spinal cord $(44,55)$.
Bonica (56) first documented targeting the sympathetic nervous system in the management of CPP in 1954. In 1990, Plancarte et al (57) reported on the reduction of pain by $70 \%$ in malignancy-induced CPP through neurolysis of the SHP and recommended it as a superior target over the lumbar sympathetic chain. In the same year, Plancarte et al (11) also published similar outcomes of patients with perineal pain (malignant and nonmalignant) who underwent neurolysis of the GI. In 2015, Ahmed at el (9) published a small study showing the efficacy of combined SHP and GI block for pelvic and/or perineal cancer pain with good relief without complications or serious side effects.

\section{METHODS}

CPP, like many pain syndromes, is responsive to nerve blocks, particularly those targeting the sympathetic nervous system (i.e., SHP and GI) $(59,60)$. Similar to other chronic pain conditions, in cases where diagnostic blocks are only temporarily effective, neurolytic procedures are indicated as a means of potentially providing longer and more sustained relief (61). To our knowledge, there has not been any reported cases of RE as a consequence of combined or serial SHP and GI neurolysis, in any combination. We present a case series of 3 patients who reported RE consequent to a SHP blockade neurolysis following a GI neurolysis.

\section{CASE SERIES}

\section{Patient 1 - JH}

$\mathrm{JH}$ is a 29-year-old male with a 4-year history of CPP. The patient reported the pain began insidiously and without incident. At the time of the initial evaluation, he reported the symptoms localized to the penis, testicles, and perineum. The quality of the pain was sharp and "needle-like." Neither a definitive diagnosis had been made for his pain or a precise mechanism for the symptoms.

His pain was erratic; however, sexual activity and sitting were the most predictable causes of pain. $\mathrm{He}$ tried several medications including acetaminophenoxycodone, baclofen, diazepam, and alprazolam with minimal pain relief. Additionally, JH had tried a series of nerve blocks (pudendal and ilioinguinal) as well as physical therapy - none of which were successful. The patient underwent a GI block with near 
complete pain relief for several hours - no complications or side effects were noted. He underwent a subsequent $\mathrm{GI}$ neurolysis with $5 \mathrm{cc}$ of $98 \%$ dehydrated ethyl alcohol injected via the trans-sacrococcygeal approach. Two weeks later the patient presented for a post-procedural follow-up at which time he reported no pain relief. The GI neurolysis was repeated one week later - this time the patient reported good relief lasting 5 to 6 months.

The pain returned 6 months later and had now spread to the inguinal region. The decision was made to repeat the $\mathrm{GI}$ neurolysis as well as perform a simultaneous neurolysis of the SHP in the hopes of capturing the inguinal pain - GI neurolysis utilized $5 \mathrm{cc}$ of $98 \%$ dehydrated alcohol; the SHP neurolysis (transdiscal approach) used a total of $14 \mathrm{cc}$ of $98 \%$ dehydrated alcohol (7cc on each side). One month later, the patient presented for follow-up. He reported near complete pain relief; however, he noted that when he achieved an orgasm during sexual activity there was no ejaculation. Eight months post-procedure, he continued to have this side effect. JH was evaluated by urology who subsequently diagnosed him with RE.

The patient was started on a combination of imipramine and midodrine that resolved the RE.

\section{Patient 2 - SD}

SD is a 44-year-old male with a 3-month history of pelvic pain. The patient reported the pain began shortly after the removal of a kidney stone that was lodged in an ejaculatory duct. The pain was sharp, shooting, and burning and radiated from his rectum to the tip of his penis and into his buttocks. It was worse with prolonged sitting and during sexual intercourse. He reported having tried a course of gabapentin that was only mildly effective. The patient underwent a GI block with near complete relief of his pain for several hours with no complications or unwanted side effects noted. Subsequently, he underwent a GI neurolysis with $6 \mathrm{cc}$ of $98 \%$ dehydrated ethyl alcohol injected via the trans-sacrococcygeal approach. Two weeks later, the patient presented for post-procedural follow-up. $\mathrm{He}$ reported the posterior, perineal pain was greatly improved. However, he still had a significant amount of pain at the tip of his penis.

Two weeks later, the patient presented for a SHP block - transdiscal approach with $14 \mathrm{cc}$ of $0.25 \%$ bupivacaine (7cc on each side). He reported that his pain improved by $50 \%$ for nearly 24 hours; however, he noted during that time he was unable to ejaculate when he achieved an orgasm. As the pain returned, he was once again able to ejaculate. The SHP block was repeated one week later with the same result; therefore, the decision was made to abort any plans for neurolysis to the SHP.

\section{Patient 3 - MB}

$M B$ is a 24-year-old male with a 6-year history of CPP. The patient reported the pain started gradually as discomfort in the left testicle, without incident or trauma, accompanied by low libido and post-ejaculatory pain. Over time, the pain in the left testicle subsided, however he now complained of chronic pelvic floor pain and erectile dysfunction, as well as post-ejaculatory rectal/penile pain. No definitive diagnosis had been made for his pain or a precise mechanism for the symptoms.

He reported the pain radiated up the inguinal region during ejaculation and occasionally into the left leg. The patient received a Gl block that provided good, albeit temporary relief to the pelvic floor and genital region; however, the pain radiating into the leg was unchanged - no complications or side effects were noted. A GI block was repeated one week later with the same result. Subsequently, he underwent a GI neurolysis with 3cc of $98 \%$ dehydrated ethyl alcohol injected via the trans-sacrococcygeal approach. Two weeks later, the patient presented for post-procedural follow-up. He reported only transient relief from the $\mathrm{GI}$ neurolysis, thus the decision was made to proceed with a diagnostic block of the SHP.

After another 2 weeks, the patient presented for a SHP block - transdiscal approach with $14 \mathrm{cc}$ of $0.25 \%$ bupivacaine (7cc on each side). The patient followed-up one week later. He reported good relief of the majority of the areas of his pain for the remainder of the day after the block (approximately 10 to 12 hours). However, during that time he reported he was unable to ejaculate during orgasm. As the pain returned, his ability to ejaculate returned. The SHP block was repeated one week later with the same result; therefore, the decision was made to abort any plans for neurolysis to the SHP.

\section{DISCUSSION}

Ejaculation is a complex and synchronized process, 
coordinated by the sympathetic nervous system. Signals travel caudally from the lumbar sympathetic chains to SHP and GI into the bladder, testicles, and penis to initiate the emission phase of ejaculation and bladder neck closure under high pressure $(37,62)$. This pressure gradient created by the bladder neck musculature ensures normal antegrade ejaculation in the direction of low-pressure urethral opening. In the pathological state, contractile expulsion force overcomes the low bladder neck closure pressure to cause a backward flow of semen into the bladder and results in RE. Permanent or temporary RE following neurological injuries to anterior lumbar spine such as bilateral lumbar sympathectomy or SHP injury are well-documented in the neurosurgical literature (63-69). Similarly, RE has also been described as a complication following interventional neurolytic procedures $(70,71)$.

Traditional etiologies of RE are typically associated with $\alpha$-receptor antagonists users, individuals with chronic, uncontrolled diabetes, or patients having undergone surgical procedures involving the prostate, bladder, and the like (72). Given that these patient populations are likely to be elderly and beyond the typical reproductive age, individuals that do not wish to father children, or in those with disabling terminal cancer pain in the pelvis, RE may not be a relevant complication or issue. Ahmed et al (9) published on findings of 9 men and 6 women, ranging from 41 to 67.6 years old, with cancer-related pelvic pain receiving chemical neurolysis. The authors described the plausibility that RE may be present but go undetected or unreported. However, in younger men that undergo interventional treatment for non-oncological pelvic pain, the prevention and education of the potential $\mathrm{RE}$ risk becomes significantly important, as it is much more likely to be noticed due to potentially heighten sexual activity by comparison.

$\mathrm{RE}$ is difficult to detect/diagnose in the overall male population due to similarities to other subtypes of male sexual dysfunction, as well as the potential for underreporting stemming from the fear social stigmatization (20). Some cases are simply unavoidable, despite the best efforts to avoid this dreaded complication; however, in cases of therapeutic neurolysis of the GI and/or SHP, RE can be predicted with the use of a diagnostic blockade beforehand.
Diagnostic blocks, as a whole, serve the following purposes: to confirm/negate a potential target as a pain generator and or conduit (thus assessing the utility of destroying it), to estimate the degree of pain relief, and to assess the risks for any potential sideeffects or complications before applying irreversible neurolytic techniques. In the pelvic region, this is especially important as any reproductive and sexual dysfunctions not only cause detrimental psychosocial and reproductive impact to the patient, but the negative psychological consequences affect their partners and relationships as well $(15,21-23)$.

This case series illustrates RE as a potential complication that should be considered when blocking the SHP following, or in tandem with, a GI neurolysis. It is the recommendation of the authors that if a neurolysis of either the SHP or GI has already been performed, and one is considering targeting the other for neurolysis, 2 repeated diagnostic blocks should be performed on separate visits to assess for RE, as well as any other potential complications. This is particularly important in male patients that desire or potentially would like to father a child in the future.

We recommend $\mathrm{GI}$ to be considered as the first neurolytic target in conditions summarized in Table 2 (73). In cases where GI neurolysis alone yields incomplete pain relief, SHP may be considered as an additional neurolytic target. However, we strongly recommend 2 repeated diagnostic blocks of the SHP be performed with $0.25 \%$ or $0.5 \%$ bupivacaine as a precursor to neurolysis. Additionally, we recommend the patient, if possible, to engage in either sexual intercourse or masturbation within 6 to 8 hours of the block, as a means of potentially detecting RE during the time period while the SHP is under the influence of a sodium channel blocker. The presence of cloudy urine, fructose in the urine, and ejaculate volume less than $2 \mathrm{~mL}$ following the SHP blockage suggests RE.

In such cases where RE is suspected, using irreversible neurolytic agents such as phenol or dehydrated alcohol should be avoided to prevent permanent RE. If CPP severity necessitates additional interventions, pulsed radiofrequency ablation is a reasonable neuroIytic alternative that could preferentially target $A-\beta$ or C-fibers to interrupt pain signals, while leaving fibers responsible for physiologic ejaculation intact (74-76). Spinal cord stimulation at T11-T12 (77), dorsal root 
Table 2. Conditions in which GI blockade is considered as a first line in interventional pain procedure (73)

\begin{tabular}{|l|l|}
\hline Perineal pain, with or without malignancy & Endometriosis \\
\hline Rectal/anal pain (proctitis) & Chronic prostatitis \\
\hline Distal urethral pain & Proctalgia Fugax \\
\hline Vulvodynia & Coccygodynia \\
\hline Scrotal pain & Radiation proctitis \\
\hline Female pelvic/vaginal pain (distal 1/3) & Postherpetic neuralgia \\
\hline Localized, burning perineal pain associated with urgency & Sympathetically-maintained pain (i.e., Complex Regional Pain Syndrome) \\
\hline
\end{tabular}

ganglion stimulation (78), or pudendal nerve stimulation (79) may also serve as a viable option in patients who are unresponsive to other treatments.

\section{CONCLUSION}

$\mathrm{RE}$ is a potential consequence of combined or serial SHP and GI neurolysis; consequently, SHP and GI neurolysis should not be performed simultaneously. In patients where the GI has already been ablated, one should proceed with caution when considering interventions targeting the SHP - and reverse in cases where neurolysis of the SHP occurred first. If after neurolysis of one structure has already occurred, and the other is being considered in the pursuit of more complete pain relief, 2 diagnostic blocks should be performed before any neurolysis to assess for the possibility of RE.

\section{REFERENCES}

1. de Leon-Casasola OA. Critical evaluation of chemical neurolysis of the sympathetic axis for cancer pain. Cancer Control 2000; 7:142-148.

2. Bhatnagar S, Gupta M. Evidence-based clinical practice guidelines for interventional pain management in cancer pain. Indian J Palliat Care 2015; 21:137-147.

3. Furlan AD, Mailis A, Papagapiou M. Are we paying a high price for surgical sympathectomy? A systematic literature review of late complications. J Pain 2000; 1:245-257.

4. Kuponiyi O, Alleemudder DI, Latunde-Dada A, Eedarapalli P. Nerve injuries associated with gynaecological surgery. Obstet Gynecol 2014; 16:29-36.

5. Bloski T, Pierson R. Endometriosis and chronic pelvic pain: Unraveling the mystery behind this complex condition. Nurs Womens Health 2008; 12:382-395.

6. Ignacio EA, Dua R, Sarin S, Harper AS, Yim D, Mathur V, Venbrux AC. Pelvic congestion syndrome: Diagnosis and treatment. Semin Intervent Radiol 2008; 25:361-368.

7. Kambadakone A, Thabet A, Gervais DA, Mueller PR, Arellano RS. CT-guided celiac plexus neurolysis: A review of anatomy, indications, technique, and tips for successful treatment. Radio- graphics 2011; 31:1599-1621.

8. Vorenkamp KE, Dahle NA. Diagnostic celiac plexus block and outcome with neurolysis. Tech Reg Anesth Pain Manag 2011; 15:28-32.

9. Ahmed DG, Mohamed MF, Mohamed SA-E. Superior hypogastric plexus combined with ganglion impar neurolytic blocks for pelvic and/or perineal cancer pain relief. Pain Physician 2015; 18:E49-E56.

10. Kitoh T, Tanaka S, Ono K, Ohfusa Y, Ina H, Otagiri T. Combined neurolytic block of celiac, inferior mesenteric, and superior hypogastric plexuses for incapacitating abdominal and/or pelvic cancer pain. J Anesth 2005; 19:328-332.

11. Plancarte DR, Amescua C, Patt RB, Allende S. Presacral blockade of the ganglion of Walther (ganglion impar). Anesthesiology 1990; 73:A751.

12. Plancarte $R$, de Leon-Casasola OA, El-Helaly M, Allende S, Lema MJ. Neurolytic Superior Hypogastric Plexus Block for Chronic Pelvic Pain Associated With Cancer. Reg Anesth 1997; 22:562.

13. Mosher WD, Pratt WF. Fecundity and infertility in the United States: Incidence and trends. Fertil Steril 1991; 56:192-193. 
14. Thonneau P, Marchand S, Tallec A, Ferial M-L, Ducot B, Lansac J, Lopes P, Tabaste JM, Spira A. Incidence and main causes of infertility in a resident population $(1,850,000)$ of three French regions (1988--1989). Hum Reprod 1991; 6:811-816.

15. Smith JF, Walsh TJ, Shindel AW, Turek PJ, Wing H, Pasch L, Katz PP; Infertility Outcomes Program Project Group. Sexual, marital, and social impact of a man's perceived infertility diagnosis. J Sex Med 2009; 6:2505-2515.

16. Jefferys $A$, Siassakos $D$, Wardle $P$. The management of retrograde ejaculation: A systematic review and update. Fertil Steril 2012; 97:306-312.

17. Vernon M, Wilson E, Muse K, Estes S, Curry T. Successful pregnancies from men with retrograde ejaculation with the use of washed sperm and gamete intrafallopian tube transfer (GIFT). Fertil Steril 1988; 50:822-824.

18. Yavetz H, Yogev L, Hauser R, Lessing JB, Paz G, Homonnai ZT. Retrograde ejaculation. Hum Reprod 1994; 9:381-386.

19. Juárez-Bengoa A, Bagnarello-González F, Rodríguez-Perdomo DF, Rodríguez-Yee E. Prevalence of retrograde ejaculation in infertility associated to hypospermia. Ginecol Obstet Mex 2011; 79:61-66.

20. Laumann EO, Paik A, Rosen RC. Sexual dysfunction in the United States: Prevalence and predictors. JAMA 1999; 281:537544.

21. Norman GR, Sloan JA, Wyrwich KW. Interpretation of changes in health-related quality of life: The remarkable universality of half a standard deviation. Med Care 2003; 41:582-592.

22. Andrews FM, Abbey A, Halman LJ. Stress from infertility, marriage factors, and subjective well-being of wives and husbands. J Health Soc Behav 1991; 32:238-253.

23. Leiblum SR, Aviv A, Hamer R. Life after infertility treatment: A long-term investigation of marital and sexual function. Hum Reprod 1998; 13:3569-3574.

24. Elliott PA, Hoffman J, Abad-Santos M, Herndon C, Katz PP, Smith JF. Out-of-pocket costs for men undergoing infertility care and associated financial strain. Urology Practice 2016; 3:256261.

25. Lipshultz LI, Howards SS, Niederberger CS. Infertility in the Male. Cambridge University Press, Cambridge, 2009.

26. Girgis SM, Etriby A, el-Hefnawy H, Kahil S. Aspermia: A survey of 49 cases. Fertil Steril 1968; 19:580-588.

27. Puppo V, Puppo G. Comprehensive review of the anatomy and physiology of male ejaculation: Premature ejaculation is not a disease. Clin Anat 2016; 29:111-119

28. Robin G, Marcelli F, Mitchell V, Marchetti C, Lemaitre L, Dewailly $\mathrm{D}$, Leroy-Billiard M, Rigot J-M. Pourquoi et comment réaliser un bilan d'hypospermie? Gynécologie Obstétrique \& Fertilité 2008; 36:1035-1042.

29. Vroege JA, Gijs L, Hengeveld MW. Classification of sexual dysfunctions: Towards DSM-V and ICD-11. Compr Psychiatry 1998; 39:333-337.

30. Cruz N, Porst H. Ejaculatory and orgasmic disorders other than premature ejaculation disorders. Ejaculation/orgasmic disorders in men. In: Porst H, Reisman Y (eds). The ESSM Syllabus of Sexual Medicine. Medix Publishers, Amsterdam 2012, pp 737791.

31. Seyam R. A systematic review of the correlates and management of nonpremature ejaculatory dysfunction in heterosexual men. Ther Adv Urol 2013; 5:254-297.

32. Comer GC, Smith MW, Hurwitz EL, Mitsunaga KA, Kessler R,
Carragee EJ. Retrograde ejaculation after anterior lumbar interbody fusion with and without bone morphogenetic protein-2 augmentation: A 10-year cohort controlled study. Spine J 2012; 12:881-890.

33. Maas CP, Moriya $\mathrm{Y}$, Steup $\mathrm{WH}$, Klein Kranenbarg E, van de Velde CJ. A prospective study on radical and nerve-preserving surgery for rectal cancer in the Netherlands. Eur J Surg Oncol 2000; 26:751-757.

34. Kim NK, Aahn TW, Park JK, Lee KY, Lee WH, Sohn SK, Min JS. Assessment of sexual and voiding function after total mesorectal excision with pelvic autonomic nerve preservation in males with rectal cancer. Dis Colon Rectum 2002; 45:1178-1185.

35. Havenga K, Maas CP, DeRuiter MC, Welvaart K, Trimbos JB. Avoiding long-term disturbance to bladder and sexual function in pelvic surgery, particularly with rectal cancer. Semin Surg Oncol 2000; 18:235-243.

36. Akasu T, Sugihara K, Moriya Y. Male urinary and sexual functions after mesorectal excision alone or in combination with extended lateral pelvic lymph node dissection for rectal cancer. Ann Surg Oncol 2009; 16:2779-2786.

37. Parnham A, Serefoglu EC. Retrograde ejaculation, painful ejaculation and hematospermia. Transl Androl Urol 2016; 5:592601.

38. Dellon AL, Coady D, Harris D. Pelvic pain of pudendal nerve origin: Surgical outcomes and learning curve lessons. J Reconstr Microsurg 2015; 31:283-290.

39. Giuliano P, Bernabé J, Laurin M, Droupy S, Benoit G, Alexandre L, Clément P. 141Tamsulosin impairs bulbospongiosus muscle (BS) contractions induced by central injection of 8-hydroxy2-(DI-N-propylamino) tetralin (8-OH-DPAT) in anaesthetised rats while alfuzosin does not. European Urology Supplements 2005; $4: 38$

40. Aizenberg D, Shiloh R, Zemishlany Z, Weizman A. Low-dose imipramine for thioridazine-induced male orgasmic disorder. $J$ Sex Marital Ther 1996; 22:225-229.

41. Loh C, Leckband SG, Meyer JM, Turner E. Risperidone-induced retrograde ejaculation: Case report and review of the literature. Int Clin Psychopharmacol 2004; 19:111-112.

42. Kim SW, Paick J-S. Peripheral effects of serotonin on the contractile responses of rat seminal vesicles and vasa deferentia. $J$ Androl 2004; 25:893-899.

43. Fedder J, Kaspersen MD, Brandslund I, Højgaard A. Retrograde ejaculation and sexual dysfunction in men with diabetes mellitus: A prospective, controlled study. Andrology 2013; 1:602606.

44. Hunter C, Davé N, Diwan S, Deer T. Neuromodulation of pelvic visceral pain: Review of the literature and case series of potential novel targets for treatment. Pain Pract 2013; 13:3-17.

45. Green IC, Cohen SL, Finkenzeller D, Christo PJ. Interventional therapies for controlling pelvic pain: What is the evidence? Curr Pain Headache Rep 2010; 14: 22-32.

46. Lu S, Xu Y-Q, Chang S, Zhang Y-Z, Shi J-H, Ding Z-H, Zhong SZ. Clinical anatomy study of autonomic nerve with respective to the anterior approach lumbar surgery. Surg Radiol Anat 2009; 31:425-430.

47. Daniels IR, Woodward S, Taylor FGM, Raja A, Toomey P. Female urogenital dysfunction following total mesorectal excision for rectal cancer. World J Surg Oncol 2006; 4:6.

48. Benzon H, Raja SN, Fishman SE, Liu SS, Cohen SP. Essentials of Pain Medicine - 3rd Edition. Elsevier Health Sciences, Amsterdam, 2011. 
49. Yucel S, Erdogru T, Baykara M. Recent neuroanatomical studies on the neurovascular bundle of the prostate and cavernosal nerves: Clinical reflections on radical prostatectomy. Asian J Androl 2005; 7:339-349.

50. Gupta D, Jain R, Mishra S, Kumar S, Thulkar S, Bhatnagar S. Ultrasonography reinvents the originally described technique for ganglion impar neurolysis in perianal cancer pain. Anesth Analg 2008; 107:1390-1392.

51. de Médicis É, de Leon-Casasola OA. Ganglion impar block: Critical evaluation. Tech Reg Anesth Pain Manag 2001; 5:120122.

52. Plancarte R, Amescua C, Patt RB, Allende S. Presacral neurectomy of the ganglion impar (Ganglion of Walther). Anesthesiology 1990; 73:A751.

53. Agarwal-Kozlowski K, Lorke DE, Habermann CR, Am Esch JS, Beck H. CT-guided blocks and neuroablation of the ganglion impar (Walther) in perineal pain: Anatomy, technique, safety, and efficacy. Clin J Pain 2009; 25:570-576.

54. Toshniwal GR, Dureja GP, Prashanth SM. Transsacrococcygeal approach to ganglion impar block for management of chronic perineal pain: A prospective observational study. Pain Physician 2007; 10:661-666.

55. Zondervan KT, Yudkin PL, Vessey MP, Jenkinson CP, Dawes MG, Barlow DH, Kennedy SH. Chronic pelvic pain in the community--symptoms, investigations, and diagnoses. Am J Obstet Gynecol 2001; 184:1149-1155.

56. Bonica JJ. The management of pain of malignant disease with nerve blocks. Anesthesiology 1954; 15:280-291.

57. Plancarte R, Amescua C, Patt RB, Aldrete JA. Superior hypogastric plexus block for pelvic cancer pain. Anesthesiology 1990; 73:236-239.

58. Reig E, Abejón D, del Pozo C, Insausti J, Contreras R. Thermocoagulation of the ganglion impar or ganglion of Walther: Description of a modified approach. Preliminary results in chronic, nononcological pain. Pain Pract 2005; 5:103-110.

59. de Leon-Casasola OA, Kent E, Lema MJ. Neurolytic superior hypogastric plexus block for chronic pelvic pain associated with cancer. Pain 1993; 54:145-151.

60. Scott-Warren JT, Hill V, Rajasekaran A. Ganglion impar blockade: A review. Curr Pain Headache Rep 2013; 17:306

61. Mishra S, Bhatnagar S, Rana SPS, Khurana D, Thulkar S. Efficacy of the anterior ultrasound-guided superior hypogastric plexus neurolysis in pelvic cancer pain in advanced gynecological cancer patients. Pain Med 2013; 14:837-842.

62. Böhlen D, Hugonnet CL, Mills RD, Weise ES, Schmid HP. Five meters of $\mathrm{H}(2) \mathrm{O}$ : The pressure at the urinary bladder neck during human ejaculation. Prostate 2000; 44:339-341.

63. Ikard RW. Methods and complications of anterior exposure of the thoracic and lumbar spine. Arch Surg 2006; 141:1025-1034.
64. Kang B-U, Choi W-C, Lee S-H, Jeon SH, Park JD, Maeng DH, Choi Y-G. An analysis of general surgery--related complications in a series of 412 minilaparotomic anterior lumbosacral procedures: Clinical article. J Neurosurg Spine 2009; 10:60-65.

65. Rajaraman V, Vingan R, Roth P, Heary RF, Conklin L, Jacobs GB. Visceral and vascular complications resulting from anterior lumbar interbody fusion. J Neurosurg 1999; 91:60-64.

66. Regan JJ, Yuan H, McAfee PC. Laparoscopic fusion of the lumbar spine: Minimally invasive spine surgery. A prospective multicenter study evaluating open and laparoscopic lumbar fusion. Spine 1999; 24:402-411.

67. Samudrala S, Khoo LT, Rhim SC, Fessler RG. Complications during anterior surgery of the lumbar spine: An anatomically based study and review. Neurosurg Focus 1999; 7:e9.

68. Sasso RC, Best NM, Mummaneni PV, Reilly TM, Hussain SM. Analysis of operative complications in a series of 471 anterior lumbar interbody fusion procedures. Spine 2005; 30:670-674.

69. Saraph V, Lerch C, Walochnik N, Bach CM, Krismer M, Wimmer C. Comparison of conventional versus minimally invasive extraperitoneal approach for anterior lumbar interbody fusion. Eur Spine J 2004; 13:425-431.

70. Ishizaki K, Shiga T, Kitani Y, Fujita T. Two types of ejaculatory failure after chemical sympathectomy. Pain Clin 1993; 6:31-33.

71. Shin SK, Kweon TD, Ha SH, Yoon KB. Ejaculatory failure after unilateral neurolytic celiac plexus block. Korean J Pain 2010; 23:274-277.

72. Althof SE. Prevalence, characteristics and implications of premature ejaculation/rapid ejaculation. J Urol 2006; 175:842-848.

73. Hunter CW, Diwan S. Ganglion Impar Block. In: Staats P, Diwan $\mathrm{S}$ (eds). Atlas of Pain Medicine Procedures. McGraw-Hill Education, New York, 2014.

74. Hamann W, Abou-Sherif S, Thompson S, Hall S. Pulsed radiofrequency applied to dorsal root ganglia causes a selective increase in ATF3 in small neurons. Eur J Pain 2006; 10:171-176.

75. Erdine S, Bilir A, Cosman ER, Cosman ER Jr. Ultrastructural changes in axons following exposure to pulsed radiofrequency fields. Pain Pract 2009; 9:407-417.

76. Bogduk N. Pulsed radiofrequency. Pain Med 2006; 7:396-407.

77. Kapural L, Narouze SN, Janicki TI, Mekhail N. Spinal cord stimulation is an effective treatment for the chronic intractable visceral pelvic pain. Pain Med 2006; 7:440-443.

78. Rowland DCL, Wright D, Moir L, FitzGerald JJ, Green AL. Successful treatment of pelvic girdle pain with dorsal root ganglion stimulation. Br J Neurosurg 2016; 30:685-686.

79. Peters KM, Killinger KA, Boguslawski BM, Boura JA. Chronic pudendal neuromodulation: Expanding available treatment options for refractory urologic symptoms. Neurourol Urodyn 2010; 29:1267-1271. 